\title{
PENDUGAAN PARAMETER DARI DISTRIBUSI POISSON DENGAN MENGGUNAKAN METODE MAXIMUM LIKEHOOD ESTIMATION (MLE) DAN METODE BAYES
}

\author{
MEUTIA FIKHRI, FERRA YANUAR, YUDIANTRI ASDI \\ Program Studi Matematika, \\ Fakultas Matematika dan Ilmu Pengetahuan Alam, Universitas Andalas, \\ Kampus UNAND Limau Manis Padang, Indonesia, \\ fikhrimeutia@ymail.com
}

\begin{abstract}
Abstrak. Pendugaan titik dari sebuah parameter populasi adalah sebuah nilai yang diperoleh dari contoh dan digunakan sebagai penduga dari parameter yang nilainya tidak diketahui. Pendugaan titik dapat ditentukan dengan beberapa metode pendugaan, yaitu metode Momen, metode Maksimum Likelihood Estimation (MLE) dan metode Bayes. Tujuan dari penelitian ini adalah untuk menentukan pendugaan titik pada distribusi Poisson untuk satu parameter dengan metode Maksimum Likelihood Estimation (MLE) dan metode Bayes dan membandingkan kedua metode dalam menduga parameter distribusi Poisson. Distribusi Prior untuk metode Bayes yang digunakan pada penelitian ini adalah distribusi prior Gamma. Perbandingan kedua metode dilakukan melalui simulasi data pada berbagai kondisi parameter dan ukuran sampel, kemudian dilihat ketakbiasan, kekonsistenan, dan keefisienan. Hasil simulasi data menunjukkan bahwa metode Bayes lebih konsisten dibandingkan dengan metode Maksimum Likelihood Estimation (MLE) dalam menduga parameter distribusi Poisson.
\end{abstract}

Kata Kunci: Distribusi Poisson, Distribusi Gamma, Metode Maximum Likelihood Estimation (MLE), Metode Bayes, Metode Evaluasi Pendugaan

\section{Pendahuluan}

Statistika adalah suatu ilmu yang berisi sejumlah aturan dan prosedur untuk mengumpulkan data, menyajikan data, menganalisa data, serta menginterpretasikannya. Metode statistika terbagi dua, yaitu statistika deskriptif dan statistika inferensi. Statistika inferensi dapat dikelompokkan ke dalam dua bidang utama, yaitu pendugaan parameter dan pengujian hipotesis. Pendugaan parameter merupakan suatu cara untuk memprediksi karakteristik dari suatu populasi berdasarkan contoh yang diambil. Terdapat dua jenis pendugaan parameter dalam statistika, yaitu pendugaan titik dan pendugaan selang. Pendugaan titik dari sebuah parameter populasi adalah sebuah nilai yang diperoleh dari contoh dan digunakan sebagai penduga dari parameter yang nilainya tidak diketahui.

Beberapa metode pendugaan titik yang digunakan untuk menduga parameter diantaranya metode momen, metode Maximum Likelihood Estimation (MLE) dan metode Bayes. Metode momen menduga parameter dengan cara menyamakan momen contoh ke- $k$ dengan momen populasi ke- $k$ dan menyelesaikan sistem persamaan 
yang dihasilkan. Selanjutnya metode MLE merupakan suatu metode pendugaan parameter yang memaksimumkan fungsi kemungkinan. Kemudian metode Bayes merupakan metode pendugaan yang menggabungkan distribusi prior dan distribusi contoh. Distribusi prior adalah distribusi awal yang memberi informasi tentang parameter. Distribusi contoh yang digabung dengan distribusi prior akan menghasilkan suatu distribusi baru yaitu distribusi posterior yang selanjutnya menjadi dasar untuk pendugaan parameter di dalam metode Bayes.

Pada saat sekarang ini, telah banyak penelitian yang dilakukan mengenai pendugaan parameter dengan menggunakan berbagai metode dari berbagai distribusi. Dalam penelitian ini dilakukan pengkajian mengenai pendugaan parameter dari distribusi Poisson dengan metode Maximum Likelihood Estimation (MLE) dan metode Bayes. Hasil pendugaan parameter dari distribusi Poisson dengan metode MLE dan metode Bayes ini akan dibandingkan dengan menggunakan simulasi, kemudian dilihat ketakbiasan, keefisienan dan kekonsistenan pada kedua metode.

\section{Pendugaan Parameter Distribusi Poisson Menggunakan Metode Maximum Likelihood Estimation (MLE)}

Misalkan $X_{1}, X_{2}, \ldots, X_{n}$ adalah contoh acak Poisson $(\mu)$, maka fungsi kemungkinan-nya adalah

$$
\begin{aligned}
L(\mu) & =f\left(x_{1}, x_{2}, \cdots, x_{n} ; \mu\right) \\
& =\prod_{i=1}^{n} f\left(x_{i} ; \mu\right) \\
& =\prod_{i=1}^{n} \frac{e^{-\mu} \mu^{x_{i}}}{x_{i} !} \\
& =\frac{e^{-n \mu} \mu^{\sum x_{i}}}{\prod_{i=1}^{n} x_{i} !}
\end{aligned}
$$

Logaritma natural dari fungsi kemungkinannya adalah

$$
\begin{aligned}
\ln L(\mu) & =\ln \frac{e^{-n \mu} \mu^{\sum x_{i}}}{\prod_{i=1}^{n} x_{i} !} \\
& =\ln e^{-n \mu}+\ln \mu^{\sum x_{i}}-\ln \prod_{i=1}^{n} x_{i} ! \\
& =-n \mu \ln e+\sum x_{i} \ln \mu-\ln \prod_{i=1}^{n} x_{i} !
\end{aligned}
$$


154 Meutia Fikhri dkk.

Dengan mendiferensialkan terhadap $\mu$, maka diperoleh

$$
\begin{aligned}
\frac{d \ln L(\mu)}{d \mu} & =0 \\
-n+\frac{\sum x_{i}}{\mu} & =0 \\
\frac{\sum x_{i}}{\mu} & =n \\
\mu & =\frac{\sum x_{i}}{n} .
\end{aligned}
$$

Selanjutnya akan dilakukan uji turunan kedua untuk menunjukkan bahwa $\widehat{\mu}$ benarbenar memaksimumkan fungsi kemungkinan $L(\mu)$

$$
\frac{d^{2} \ln L(\mu)}{d^{2} \mu}=-\frac{\sum x_{i}}{\mu^{2}}<0 .
$$

Karena $\widehat{\mu}$ memaksimumkan fungsi kemungkinan $L(\mu)$, maka penduga untuk parameter $\mu$ menggunakan metode Maximum Likelihood Estimation (MLE) adalah

$$
\widehat{\mu}_{M L E}=\frac{\sum x_{i}}{n} .
$$

\section{Pendugaan Parameter Distribusi Poisson Menggunakan Metode Bayes}

Misalkan $X_{1}, X_{2}, \cdots, X_{n}$ adalah peubah acak dari distribusi Poisson $(\mu)$. Fungsi kemungkinan dari distribusi Poisson $(\mu)$ adalah

$$
\begin{aligned}
L(\mu) & =f\left(x_{1}, x_{2}, \cdots, x_{n} ; \mu\right) \\
& =\prod_{i=1}^{n} f\left(x_{i} ; \mu\right) \\
L(\mu) & =\prod_{i=1}^{n} \frac{e^{-\mu} \mu^{x_{i}}}{x_{i} !} \\
& =\frac{e^{-n \mu} \mu^{\sum x_{i}}}{\prod_{i=1}^{n} x_{i} !} .
\end{aligned}
$$

Prior sekawan untuk distribusi Poisson dengan parameter $\mu$ akan memiliki bentuk yang sama sebagai fungsi kemungkinan, yaitu memiliki bentuk

$$
L(\mu) \propto e^{-n \mu} \mu^{\Sigma x_{i}} .
$$

Distribusi yang memiliki bentuk seperti ini adalah distribusi Gamma $(\alpha, \beta)$, yang memiliki bentuk fungsi kepekatan peluang :

$$
f(\mu ; \alpha, \beta)=\frac{1}{\beta^{\alpha} \Gamma(\alpha)} \mu^{\alpha-1} e^{-\frac{\mu}{\beta}},
$$

dengan $\alpha-1=\Sigma x_{i}, \frac{1}{\beta}=n$ dan $\frac{1}{\beta^{\alpha} \Gamma(\alpha)}$ adalah faktor yang dibutuhkan untuk membuat fungsi kepekatan peluang tersebut. 
Dalam teorema Bayes setelah data diambil dan prior telah ditentukan, maka kemudian dicari distribusi posteriornya, yaitu

$$
f(\mu \mid x)=\frac{f(\mu) f(x \mid \mu)}{\int_{0}^{\infty} f(\mu) f(x \mid \mu) d \mu} .
$$

Jika $X \sim \operatorname{Poisson}(\mu)$ dan distribusi prior $\mu \sim G A M(\alpha, \beta)$, maka distribusi posterior dapat dinyatakan sebagai fungsi bersyarat dari $\mu$ dengan $x$ diketahui, sehingga berdasarkan Definisi 2.2.20 dapat ditulis dengan

$$
f(\mu \mid x)=\frac{f(\mu, x)}{f(x)} .
$$

Karena $f(\mu, x)$ dapat dinyatakan dengan $f(x) f(\mu \mid x)$ atau $f(\mu) f(x \mid \mu)$, maka

$$
\begin{gathered}
f(\mu) f(x \mid \mu)=\frac{\mu^{\alpha-1} e^{-\frac{\mu}{\beta}}}{\beta^{\alpha} \Gamma(\alpha)} \frac{e^{-n \mu \mu^{\Sigma x_{i}}}}{\prod_{i=1}^{n} x_{i} !} \\
\frac{\mu^{\alpha-1+\Sigma x_{i}} e^{-\mu\left(n+\frac{1}{\beta}\right)}}{\beta^{\alpha} \Gamma(\alpha) \prod_{i=1}^{n} x_{i} !}
\end{gathered}
$$

Selanjutnya perhatikan $f(x)$, dimana $f(x)$ merupakan fungsi marginal dari $x$, sebagai berikut.

$$
\begin{aligned}
f(x) & =\int_{0}^{\infty} f(\mu, x) d \mu \\
& =\int_{0}^{\infty} f(\mu) f(x \mid \mu) d \mu \\
& =\int_{0}^{\infty} \frac{\mu^{\alpha-1+\Sigma x_{i}} e^{-\mu\left(n+\frac{1}{\beta}\right)}}{\beta^{\alpha} \Gamma(\alpha) \prod_{i=1}^{n} x_{i} !} d \mu \\
& =\frac{1}{\beta^{\alpha} \Gamma(\alpha) \prod_{i=1}^{n} x_{i} !} \int_{0}^{\infty} \mu^{\alpha-1+\Sigma x_{i}} e^{-\mu\left(n+\frac{1}{\beta}\right)} d \mu \\
& =\frac{1}{\beta^{\alpha} \Gamma(\alpha) \prod_{i=1}^{n} x_{i} !} \Gamma\left(\alpha+\Sigma x_{i}\right)\left(\left(n+\frac{1}{\beta}\right)^{-1}\right)^{\alpha+\Sigma x_{i}}
\end{aligned}
$$

Dengan persamaan (3.2), (3.3), dan (3.4), distribusi posterior dapat ditulis sebagai

$$
\begin{aligned}
f(\mu \mid x) & =\frac{f(\mu) f(x \mid \mu)}{\int_{0}^{\infty} f(\mu) f(x \mid \mu) d \mu} \\
& =\frac{\frac{\mu^{\alpha-1+\Sigma x_{i}} e^{-\mu\left(n+\frac{1}{\beta}\right)}}{\beta^{\alpha} \Gamma(\alpha) \prod_{i=1}^{n} x_{i} !}}{\frac{\Gamma\left(\alpha+\Sigma x_{i}\right)\left(\left(n+\frac{1}{\beta}\right)^{-1}\right)^{\alpha+\Sigma x_{i}}}{\beta^{\alpha} \Gamma(\alpha) \prod_{i=1}^{n} x_{i} !}} \\
f(\mu \mid x) & =\frac{e^{-\mu\left(n+\frac{1}{\beta}\right)} \mu^{\alpha-1+\Sigma x_{i}}}{\Gamma\left(\alpha+\Sigma x_{i}\right)\left(\left(n+\frac{1}{\beta}\right)^{-1}\right)^{\alpha+\Sigma x_{i}}}
\end{aligned}
$$

Berdasarkan persamaan (3.5) dapat diketahui bahwa distribusi posterior diatas merupakan distribusi Gamma dengan parameternya $\alpha+\Sigma x_{i}$ dan $\left(n+\frac{1}{\beta}\right)^{-1}$ atau $\mu \sim \operatorname{GAM}\left(\alpha+\Sigma x_{i},\left(n+\frac{1}{\beta}\right)^{-1}\right)$. 
Nilai rata-rata posterior dijadikan sebagai penduga parameter $\mu$ dalam metode Bayes [8]. Berdasarkan Teorema dinyatakan bahwa jika $X \sim G A M(\alpha, \beta)$ maka $\mu=$ $E(X)=\alpha \beta$. Dengan demikian penduga Bayes untuk parameter $\mu$, yang dinyatakan dengan $\widehat{\mu}_{B}$ adalah

$$
\widehat{\mu}_{B}=\frac{\alpha+\Sigma x_{i}}{n+\frac{1}{\beta}}
$$

\section{Evaluasi Sifat Penduga}

\subsection{Sifat Tak Bias dari Nilai Dugaan $\mu$ dengan Menggunakan metode Maximum Likelihood Estimation (MLE)}

Jika $X_{1}, X_{2}, \cdots, X_{n}$ adalah contoh acak Poisson $(\mu)$ dan diketahui penduga MLE nya adalah $\widehat{\mu}_{M L E}=\frac{\Sigma x_{i}}{n}$, maka nilai harapan $\widehat{\mu}$ adalah

$$
\begin{aligned}
E\left(\widehat{\mu}_{M L E}\right) & =E\left(\frac{\Sigma X_{i}}{n}\right) \\
& =\frac{1}{n} E\left(\Sigma X_{i}\right) \\
& =\frac{1}{n} \Sigma E\left(X_{i}\right) \\
& =\frac{1}{n} \Sigma \mu \\
& =\frac{1}{n} n \mu \\
& =\mu
\end{aligned}
$$

Karena $E\left(\widehat{\mu}_{M L E}\right)=\mu$, maka $\widehat{\mu}_{M L E}$ merupakan penduga tak bias bagi $\mu$.

\subsection{Sifat Tak Bias dari Nilai Dugaan $\mu$ dengan Menggunakan Metode Bayes}

Misalkan $X_{1}, X_{2}, \cdots, X_{n}$ adalah contoh acak Poisson $(\mu)$. Diketahui $\widehat{\mu}_{B}=\frac{\alpha+\Sigma x_{i}}{n+\frac{1}{\beta}}$ merupakan pendugaan Bayes untuk parameter $\mu$, maka nilai harapan dari pendugaan Bayes $\widehat{\mu}_{B}$ adalah

$$
\begin{aligned}
E\left(\widehat{\mu}_{B}\right) & =E\left(\frac{\alpha+\Sigma X_{i}}{n+\frac{1}{\beta}}\right) \\
& =\frac{1}{n+\frac{1}{\beta}} E\left(\alpha+\Sigma X_{i}\right) \\
& =\frac{1}{n+\frac{1}{\beta}} E(\alpha)+E\left(\Sigma X_{i}\right) \\
& =\frac{1}{n+\frac{1}{\beta}} E(\alpha)+\Sigma E\left(X_{i}\right) \\
& =\frac{1}{n+\frac{1}{\beta}}(\alpha+n \mu)
\end{aligned}
$$


Karena $E\left(\widehat{\mu}_{B}\right) \neq \mu$, maka $\widehat{\mu}_{B}$ merupakan penduga bias bagi $\mu$. Tetapi secara asimtotik tidak bias karena $\lim _{n \rightarrow \infty} E(\widehat{\mu})=\mu$

$$
\begin{aligned}
\lim _{n \rightarrow \infty} \frac{1}{n+\frac{1}{\beta}}(\alpha+n \mu) & =\lim _{n \rightarrow \infty} \frac{\alpha+n \mu}{n+\frac{1}{\beta}} \\
& =\lim _{n \rightarrow \infty} \frac{\frac{\alpha}{n}+\frac{n \mu}{n}}{\frac{n}{n}+\frac{1 / \beta}{n}} \\
& =\lim _{n \rightarrow \infty} \frac{\frac{\alpha}{n}+\mu}{1+\frac{1}{n \beta}} \\
& =\frac{\mu}{1} \\
& =\mu
\end{aligned}
$$

\section{Membandingkan sifat penduga parameter $\mu$ antara metode Maximum Likelihood Estimation (MLE) dan metode Bayes}

Penduga yang diperoleh dengan menggunakan metode Maximum Likelihood Estimation (MLE) dan metode Bayes akan dibandingkan menggunakan simulasi. Simulasi data dilakukan dengan program $\mathrm{R}$, yaitu membangkitkan data berdistribusi Poisson dengan $\mu=1.5, \mu=1.5, \mu=1$, serta lima macam ukuran sampel yaitu $\mathrm{n}=25,50,100,500,1000$. Kemudian dilakukan perulangan sebanyak 500 kali. Selanjutnya dihitung nilai rata-rata dan nilai Mean Square Error (MSE) dari kedua metode.

Nilai rata-rata dan nilai Mean Square Error (MSE) ditampilkan pada tabel 1 dan tabel 2

Tabel 1. Rata-rata nilai dugaan dengan Metode Maximum Likelihood Estimation (MLE) dan Metode Bayes

\begin{tabular}{|c|c|c|}
\hline \multirow{3}{*}{$n$} & \multicolumn{2}{|c|}{ Nilai Rata-rata } \\
\cline { 2 - 3 } & MLE & Bayes \\
\cline { 2 - 3 } & $\mu=1.5$ & $\begin{array}{c}\mu=1.5, \\
\alpha=1.5, \beta=1\end{array}$ \\
\hline 25 & 1.51024 & 1.51469 \\
\hline 50 & 1.49208 & 1.49098 \\
\hline 100 & 1.49944 & 1.49954 \\
\hline 500 & 1.49998 & 1.50037 \\
\hline 1000 & 1.50005 & 1.49998 \\
\hline
\end{tabular}

Tabel 1 dan 2 menunjukkan nilai rata-rata dan nilai MSE yang berbeda dari 
Tabel 2. Nilai Mean Square Error (MSE) dengan Metode Maximum Likelihood Estimation (MLE) dan Metode Bayes

\begin{tabular}{|c|c|c|}
\hline \multirow{3}{*}{$n$} & \multicolumn{2}{|c|}{ Nilai MSE } \\
\cline { 2 - 3 } & MLE & $\underline{\text { Bayes }}$ \\
\cline { 2 - 3 } & $\mu=1.5$ & $\begin{array}{c}\mu=1.5, \\
\alpha=1.5, \beta=1\end{array}$ \\
\hline 25 & & 0.05229 \\
\hline 50 & 0.03018 & 0.02900 \\
\hline 100 & 0.01511 & 0.01398 \\
\hline 500 & 0.00317 & 0.00305 \\
\hline 1000 & 0.00147 & 0.00139 \\
\hline
\end{tabular}

masing-masing metode. Terlihat bahwa semakin besar ukuran contoh, nilai ratarata pada kedua metode semakin mendekati nilai $\mu$, dan nilai MSE yang dihasilkan semakin kecil dan mendekati 0. Metode Bayes menghasilkan nilai MSE yang lebih kecil dibandingkan dengan metode MLE.

\section{Kesimpulan}

Kesimpulan yang dapat diambil dari penelitian yang telah dilakukan antara lain:

1. a. Penduga parameter $\mu$ dengan metode Maximum Likelihood Estimation (MLE) untuk distribusi Poisson $(\mu)$ jika dinyatakan sebagai $\widehat{\mu}$ dapat dirumuskan sebagai

$$
\widehat{\mu}=\frac{\sum x_{i}}{n}
$$

b. Penduga parameter $\mu$ dengan metode Bayes untuk distribusi Poisson $(\mu)$ jika dinyatakan sebagai $\widehat{\mu}_{B}$ dapat dirumuskan sebagai

$$
\widehat{\mu}_{B}=\frac{\alpha+\Sigma x_{i}}{n+\frac{1}{\beta}}
$$

2. Secara teoritis, pendugaan parameter dengan metode MLE adalah penduga tak bias dan metode Bayes adalah penduga bias bagi parameter $\mu$ dari distribusi Poisson. Namun penduga Bayes adalah penduga tak bias asimtotik bagi parameter $\mu$. Karena kedua penduga adalah penduga tak bias dan penduga bias, sehingga tidak bisa dibandingkan keefisienan dari penduga kedua metode, karena keefisienan penduga berlaku untuk penduga yang tak bias. Pada tabel 1 dan 2, terlihat bahwa semakin besar ukuran contoh, nilai rata-rata pada kedua metode semakin mendekati nilai $\mu$, dan nilai MSE yang dihasilkan semakin kecil dan mendekati 0. Metode Bayes menghasilkan nilai MSE yang lebih kecil dibandingkan dengan metode MLE. Sehingga pendugaan parameter $\mu$ dari distribusi Poisson dengan metode Bayes lebih konsisten dibandingkan dengan metode MLE. 


\section{Ucapan Terima kasih}

Penulis mengucapkan terima kasih kepada Bapak Dr. Dodi Devianto, Ibu Dr. Maiyastri, dan Ibu Dr. Lyra Yulianti yang telah memberikan masukan dan saran sehingga paper ini dapat diselesaikan dengan baik.

\section{Daftar Pustaka}

[1] Al-Kutubi HS, Ibrahim NA. 2009. Bayes Estimator for Exponential Distribution with Extension of Jeffrey Prior Information. Malaysian Journal of Mathematical Sciences. 3(2): 297-313.

[2] Bain, L.J and Engelhardt, M. 1992. Introduction to Probability and Mathematical Statistics Second Edition. Duxbury Press, California.

[3] Bolstad, W.M. 2007. Introduction to Bayesian Statistics Second Edition. A John Wiley dan Sons Inc Publication, America.

[4] Casella, G and R.L. Berger. 2001. Statistical Inference Second Edition. Pacific Grove, California.

[5] Nurlaila Dwi, Dadan Kusnandar, dan Evy Sulistianingsih. 2013. Perbandingan Metode Maximum Likelihood Estimation (MLE) dan Metode Bayes dalam Pendugaan Parameter Distribusi Eksponensial. Buletin Ilmiah Mat.Stat dan terapannya.

[6] Pradhan B, Kundu D. 2008. Bayes Estimation and Prediction of the TwoParameter Gamma Distribution. Applied Mathematical Sciences. 2(51):25212530.

[7] Walpole, R.E. 1993. Pengantar Statistika Edisi ke-3. PT Gramedia Pustaka Utama, Jakarta.

[8] Walpole, R.E dan Myers, R.H. 1995. Ilmu Peluang dan Statistika untuk Insinyur dan Ilmuwan. ITB, Bandung. 